\title{
DIAGNOSIS OF LUMBAR DISC PROTRUSION
}

\author{
A COMPARISON BETWEEN MAGNETIC RESONANCE IMAGING AND \\ RADICULOGRAPHY
}

\author{
E. P. SZYPRYT, P. TWINING, G. P. WILDE, R. C. MULHOLLAND, B. S. WORTHINGTON
}

From Harlow Wood Orthopaedic Hospital and the University Hospital, Nottingham

\begin{abstract}
Forty-two consecutive patients with suspected lumbar disc protrusions were studied prospectively to compare the diagnostic accuracy of low-field strength MRI with that of radiculography. Thirty patients subsequently underwent surgical exploration at 33 levels and the operative findings were compared to both methods of diagnostic imaging. All patients had MRI studies, whilst 29 patients also had radiculography. Both studies were evaluated without prior knowledge of the clinical signs, operative findings or the results of other imaging techniques.

MRI predicted the correct diagnosis in 29 of the 33 levels explored, an accuracy of $88 \%$. All discs proven to be abnormal demonstrated a reduced signal from the nucleus pulposus. There were two false positive results and two doubtful cases but no false negatives. Radiculography predicted the correct diagnosis in 24 of 32 levels explored, an accuracy of $\mathbf{7 5} \%$. There were two false positive results, five doubtfuls and one false negative. The overall accuracy when both tests were considered rose to $94 \%$. Of the remaining 12 .patients all except one showed good correlation between the MRI and radiculographic findings.

These results indicate that low field strength MRI is slightly better than radiculography in diagnosing lumbar disc protrusions.
\end{abstract}

Disorders of the spine are among the leading causes of disability affecting the adult working population. The true incidence of lumbar disc prolapse causing back pain and radicular symptoms is not known. Standard methods of radiological assessment of the site of the lesion involve both ionising radiation and often invasive procedures using intrathecal contrast media.

Radiculography is a commonly used method of identifying a prolapsed intervertebral disc, and has a sensitivity ranging from 70 to $96 \%$ (Hudgins 1970; Nachemson 1976; Haughton et al. 1982; Bell et al. 1984; Modic et al. 1986). Even with less irritant contrast media this procedure still has a significant morbidity (Grainger,

E. P. Szypryt, FRCS, Senior Registrar in Orthopaedics G. P. Wilde, FRCS, Senior Registrar in Orthopaedics

R. C. Mulholland, FRCS, Consultant Orthopaedic Surgeon

The Spinal Research Unit, Harlow Wood Orthopaedic Hospital, near Mansfield, Nottinghamshire NG18 4TH, England.

P. Twining, BSc, FRCR, Consultant Radiologist

B. S. Worthington, BSc, FRCR, Professor of Radiology

The Department of Diagnostic Radiology, University Hospital, Queens Medical Centre, Nottingham NG7 2UH, England.

Correspondence should be sent to Mr E. P. Szypryt.

(C) 1988 British Editorial Society of Bone and Joint Surgery

$0301-620 \mathrm{X} / 88 / 5183 \$ 2.00$

J Bone Joint Surg [Br] 1988;70-B:717-22.
Kendall and Wylie 1976; Baker et al. 1978), and usually requires admission to hospital.

Magnetic resonance imaging (MRI) is a noninvasive technique which does not involve ionising radiation, or any of the unpleasant effects of radiculography and it can demonstrate disc degeneration and prolapse (Chafetz et al. 1983; Han et al. 1983; Modic et al. 1984; Gibson et al. 1986a; Modic et al. 1986). When $\mathrm{T}_{2}$ weighted spin-echo sequences are employed a high signal is produced by the normal nucleus pulposus, reflecting its high water content. A degenerate or herniated disc shows a reduction in signal intensity from the nucleus pulposus. With various imaging sequences, MRI can provide not only anatomical detail but also biochemical information regarding changes in the intervertebral disc associated with degeneration and herniation.

Until recently, the major criticisms of MRI have been poor spatial resolution, large slice thickness and the inability to discriminate cortical bone from soft tissue (Han et al. 1983; Modic et al. 1983; Norman et al. 1983; Gibson et al. 1986b). The introduction of surface coil imaging, which provides an improved signal to noise ratio over a limited distance, has allowed the use of thinner slice acquisition with additional improvement in spatial resolution (Edelman et al. 1985; Schenk et al. 
1985). Modic et al. (1986) have shown that using high field strength superconductors could provide an MR examination equivalent to $\mathrm{CT}$ or myelography. If radiculography could be replaced partly or totally by MRI, using less expensive low field strength resistive magnets, patients could be studied as out-patients without invasive procedures, and with potential savings in cost. We have undertaken a preliminary prospective study to compare the efficacy of low field strength MRI to radiculography in the diagnosis of lumbar disc prolapse.

\section{MATERIALS AND METHODS}

Forty-two consecutive patients with a clinical diagnosis of prolapsed intervertebral disc form the basis of the review. All patients had intractable sciatica equal to or greater than any associated back pain, with limitation of straight leg raising and signs of root tension. Most of them had some evidence of peripheral nerve dysfunction. Patients were included in the study only when symptoms had failed to settle after a period of conservative treatment and operation was being considered. There were 28 males and 14 females aged from 16 to 58 years (mean 31.4 years). All patients had an MRI scan, 41 also had radiculography, and one had a CT scan.

Radiculography was performed using $10 \mathrm{ml}$ of metrizamide, an iodinated water soluble contrast agent, injected intrathecally. Patients were screened, using biplanar fluoroscopy, and lateral, anteroposterior and oblique radiographs were obtained. The entire lumbar spine and conus medullaris were examined routinely. The criteria for diagnosing prolapse of a disc are given by Skalpe and Amundsen (1975) and Keiffer et al. (1982). They include: angular indentation of the anterior or anterolateral aspect of the thecal sac opposite the disc space, evidence of root sheath amputation, and deviation or widening suggestive of nerve root compression (Fig. 1).

The MRI examinations were performed with the patients supine using a 0.15 Tesla resistive magnet (Picker International) with lumbar surface coils. Multislice sagittal studies ( 7 to $10 \mathrm{~mm}$ thick) were performed using (TE40/TR500 msec) T1 weighted spin-echo sequences providing good anatomical definition; (TE80/TR1000) T2 weighted spin-echo sequences and TI100/TR1100 msec Short Tau Inversion Recovery (STIR) sequence (Bydder and Young 1985) were used to highlight the signal from the nucleus pulposus and CSF. Transverse axial images $7 \mathrm{~mm}$ thick were obtained through any suspected level or levels of abnormality employing TE40/TR500 msec sequences. Selection of the correct image planes was made on a sagittal pilot scan. No facility was available to adjust the angle of acquisition at the lumbosacral level. The average scanning time was 30 minutes.

The sagittal images were evaluated for disc space

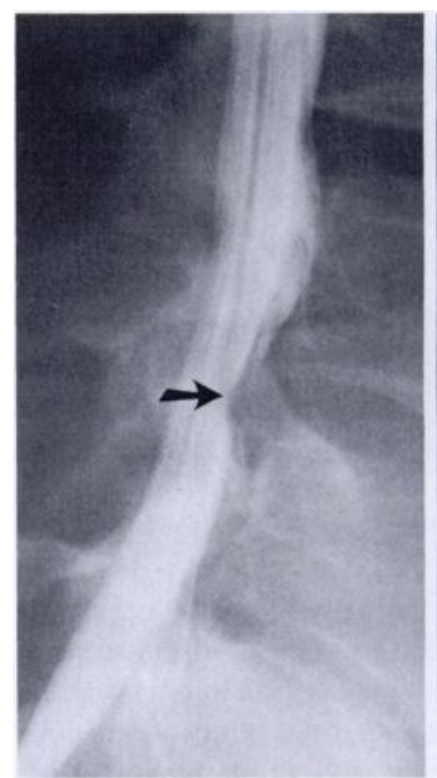

Fig. la

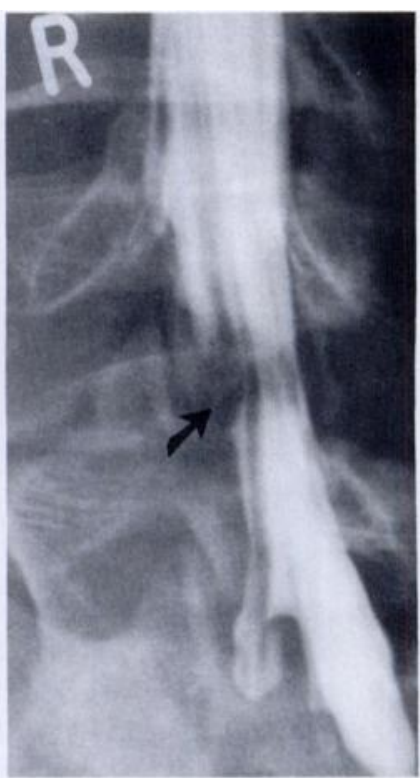

Fig. 1b
Radiculogram showing indentation of the thecal sac opposite the L4/5 disc with complete cut-off of the LS root.

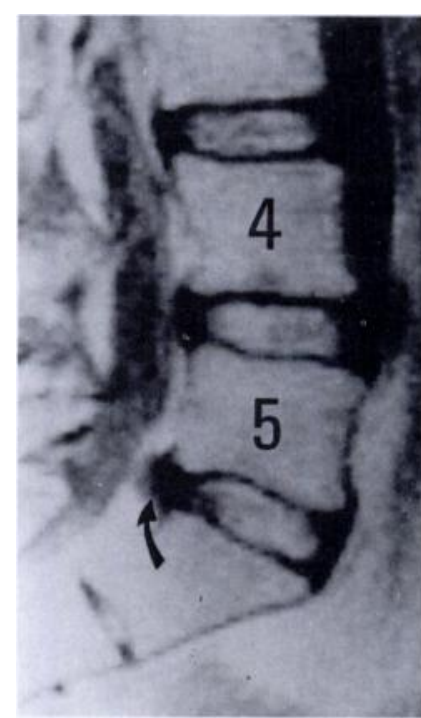

Fig. 2a

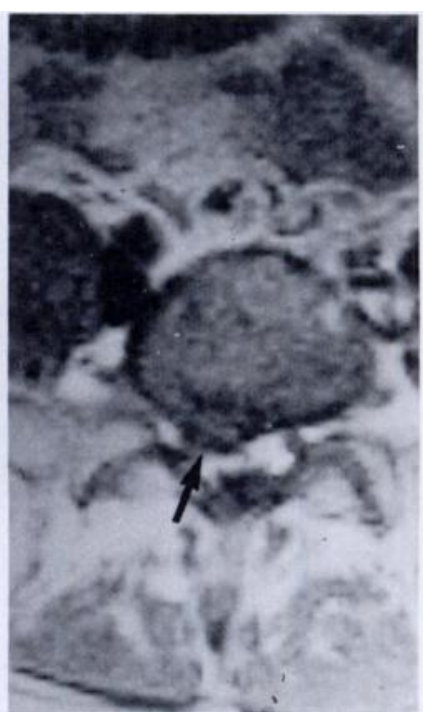

Fig. $2 b$
$T_{2}$ weighted sagittal (a) and $T_{1}$ weighted transverse (b) images showing a focal herniation of the L5/S1 disc.

height, presence of abnormal nuclear configuration and the absence of epidural fat in the lateral canal. The whole length of the spinal canal was visualised, including the conus. The signal intensity of the nucleus pulposus was assessed using the T2 weighted spin-echo and STIR images and graded on a 5 point visual scale ranging from Grade 0 (normal) to Grade 4 (complete absence of signal). The criteria for disc bulging and herniation on the MR images are similar to those of CT (Williams, Haughton and Syvertsen 1980; Williams et al. 1982), except that the tissue contrast between the thecal sac and 


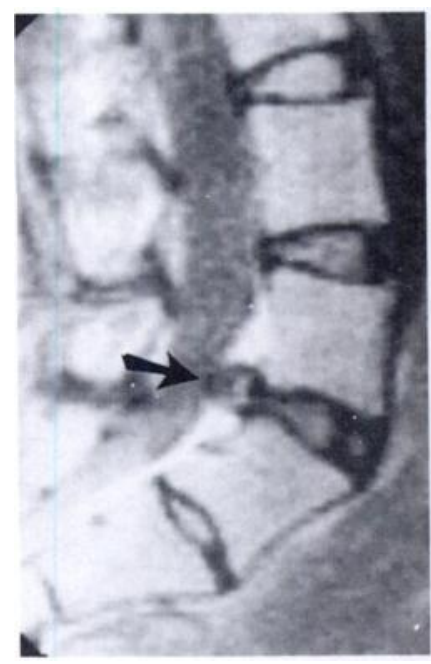

Fig. 3a

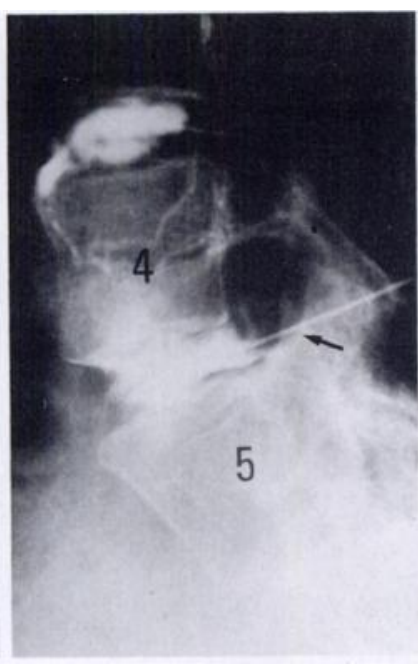

Fig. 3b
Figure 3a $-\mathrm{T}_{2}$ weighted (TE80/TR1000) sagittal image showing findings consistent with a large herniation of the L4/5 disc, and a reduction in signal from the nucleus pulposus of both $\mathrm{L} 4 / 5$ and $\mathrm{L} 3 / 4$ discs. Figure $3 b$ - Discogram of a degenerate L4/5 disc with a leak of contrast posteriorly into what was considered to be a disc herniation.

Table I. Results of three methods of imaging in 42 patients

\begin{tabular}{lccc}
\hline Diagnosis & $\begin{array}{l}\text { MRI } \\
\text { scans }\end{array}$ & Radiculography & $\begin{array}{l}\text { CT } \\
\text { scans }\end{array}$ \\
\hline Definite & 33 & 29 & 1 \\
Probable & 7 & 7 & \\
Doubtful & 1 & 4 & \\
Normal & 1 & 1 & 1 \\
Total & 42 & 41 & \\
\hline
\end{tabular}

Table II. Comparison of the results of imaging with the surgical findings in 30 patients

\begin{tabular}{lclllll}
\hline Diagnosis & $\begin{array}{l}\text { MRI } \\
\text { scans }\end{array}$ & $\begin{array}{l}\text { Confirmed } \\
\text { protrusion }\end{array}$ & $\begin{array}{l}\text { Radiculo- } \\
\text { graphy }\end{array}$ & $\begin{array}{l}\text { Confirmed } \\
\text { protrusion }\end{array}$ & $\begin{array}{l}\text { CT } \\
\text { scans }\end{array}$ & $\begin{array}{l}\text { Confirmed } \\
\text { protrusion }\end{array}$ \\
\hline Definite & 23 & 22 & 20 & 20 & 1 & 1 \\
Probable & 6 & 5 & 4 & 2 & & \\
Doubtful & 2 & 2 & 5 & 5 & & \\
Negative & 2 & 0 & 3 & 1 & & \\
Total & 33 & 29 & 32 & 28 & 1 & 1 \\
\hline
\end{tabular}

Table III. Results of imaging in 12 patients who did not have a surgical exploration

\begin{tabular}{lll}
\hline Diagnosis & MRI scans & Radiculography \\
\hline Definite & 10 & 9 \\
Probable & 1 & 3 \\
Doubtful & 0 & 0 \\
Normal & 1 & 0 \\
\hline
\end{tabular}

epidural fat is greater when employing $\mathrm{Tl}$ weighted images. Diagnostic criteria include the identification of focal extension of the disc beyond the vertebral margin, with resulting displacement of the epidural fat, nerve root, or thecal sac (Fig. 2).

The MRI scans, radiculograms and CT scan were interpreted "blind" by two of the authors without prior knowledge of the patient's clinical signs, operative findings or the result of other imaging studies. Interpretation of the investigations were dependent on three grades of certainty: definite, probable and doubtful. In the latter case the investigation was considered to be inconclusive; a further mode of imaging would have been necessary before proceeding to treatment.

\section{RESULTS}

In the 42 patients, the L5/S1 disc was implicated in 22 $(52 \%)$, the $\mathrm{L} 4 / 5$ level in $19(45 \%)$ and in one patient both levels were found to be herniated. Only 14 patients $(33 \%)$ were found to have a single disc abnormality; 18 had two degenerate discs $(43 \%)$ and 10 patients showed three abnormal discs $(24 \%)$.

Thirty of our patients had surgical exploration at 33 levels, nine were treated by chemonucleolysis, with injection into a single intervertebral disc and three had no further treatment because of spontaneous resolution of symptoms.

The degree of diagnostic certainty for each investigation is recorded in Table $\mathrm{I}$. The MRI scan predicted the presence of a disc herniation in $\mathbf{4 0}$ patients $(95 \%)$ with a reasonable degree of certainty; this compares with 36 patients $(87 \%)$ in the radiculography group. The four doubtful cases on radiculography account for this discrepancy.

Results of surgical exploration. Thirty patients had surgical exploration at 33 levels: the findings were compared with those of the imaging techniques which had been performed in these cases. The results are shown in Table II.

The MRI scan predicted the presence of a disc herniation at 29 levels, and there were no false negative and two false positive results. In one false positive the presence of bony canal stenosis in addition to a degenerate bulging disc was not appreciated on the MRI scan. In the other, a large disc protrusion at the L4/5 level was seen on the sagittal images (Fig. 3a), and confirmed by discography and radiculography (Fig. 3b). Unfortunately, because the patient became claustrophobic, the MRI had to be abandoned and transverse axial images were not obtained. At operation there was a degenerate bulging disc, but no evidence of herniated or sequestrated fragments of nuclear material were found, and despite nerve root decompression the patient's symptoms were not relieved.

One other patient showed degenerate bulging discs 
at both L4/5 and L5/S1 on MRI (Fig. 4), but because it was felt that an accurate diagnosis could not be made from this single investigation it was graded as a doubtful result. A subsequent radiculogram also identified pathology at two levels and at operation, disc protrusions were found at both levels. In all, MRI had predicted the findings of both site and type of disease in 29 of the 33 levels explored $(88 \%)$. All of the discs proved to be abnormal had given a reduced MRI signal from the nucleus pulposus.

In contrast radiculography predicted the correct diagnosis in only 24 of the 32 levels explored $(75 \%)$. The two false positive results, were from the same cases that had given rise to difficulty with interpretation of the MRI scan. In addition, there was one false negative finding and five cases where doubtful results meant that a further investigation was thought to be necessary. Four of these cases involved disc protrusions at the lumbosacral level; these were not shown clearly because of a large epidural space anterior to the thecal sac. The fifth patient with a doubtful result at two levels was the same patient whose MRI scan had also led to uncertainty. When both tests were considered the overall accuracy rose to $94 \%$.

Of the 12 patients studied but not operated upon, (Table III) nine had chemonucleolysis at a single intervertebral level. In eight of these the radiculographic and MRI findings agreed totally and the diagnosis was confirmed by discography. In the remaining case, a 44year-old man, radiculography showed a definite disc herniation at the L4/5 level (Fig. 5a) and discography confirmed an abnormal nuclear outline with a posterolateral leak of contract medium (Fig. 5b). The MRI scan was initially reported as showing a normal signal from this level with no evidence of herniation. Re-examination of these images, however, showed slight reduction in signal from the $\mathrm{L} 4 / 5$ disc, with more marked changes at the L5/S1 level (Fig. 6).

The three patients who had spontaneous resolution of symptoms before treatment had been arranged all showed good correlation between the MRI and radiculographic findings.

\section{DISCUSSION}

Since Mixter and Barr (1934) first described herniation of a lumbar intervertebral disc as a cause of nerve root compression there has been a need for a safe, accurate diagnostic tool to minimise negative explorations. It is generally considered that the decision to operate should be based on sound clinical criteria; radiological investigation should be used to complement and not replace clinical judgement. Unfortunately, clinical signs alone do not always permit accurate assessment and localisation of spinal pathology. Pre-operative investigation should confirm the diagnosis and localise the level of the lesion, helping to avoid unnecessary and
R. C. MULHOLLAND, B. S. WORTHINGTON

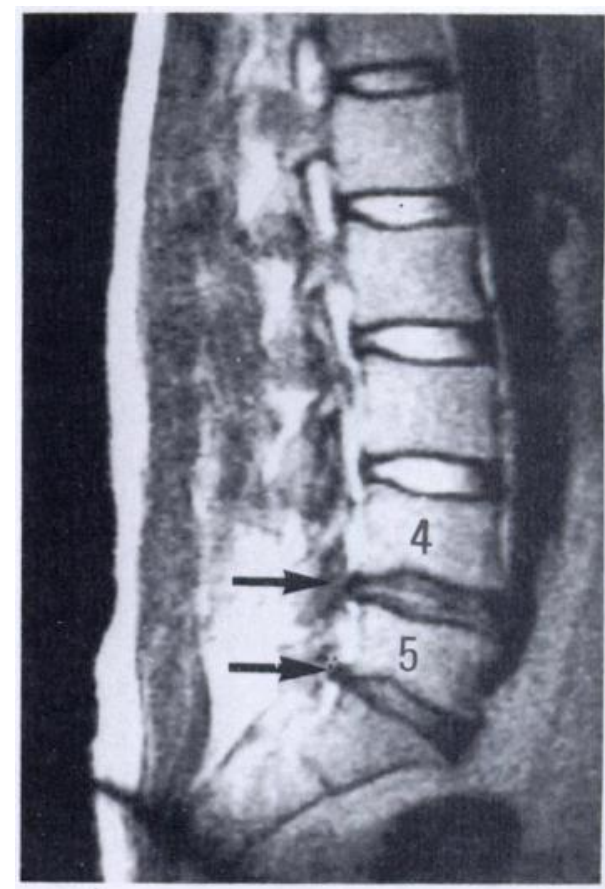

Fig. 4

$T_{2}$ weighted spin-echo (TE800/TR1000) sagittal image showing a reduction in signal and bulging at both L4/5 and L5/S1 discs.

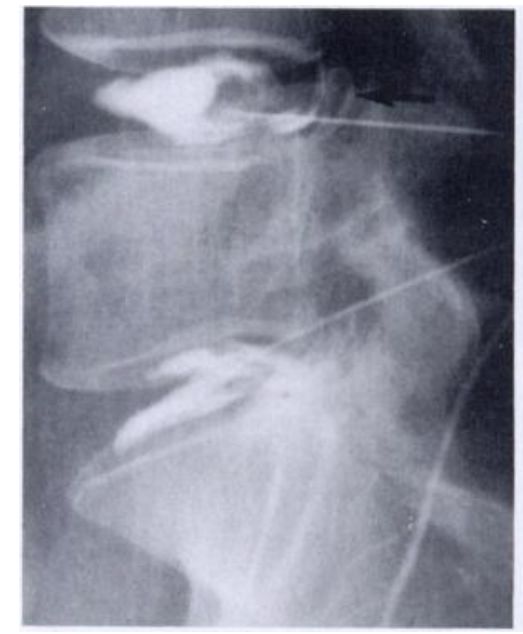

Fig. 5a

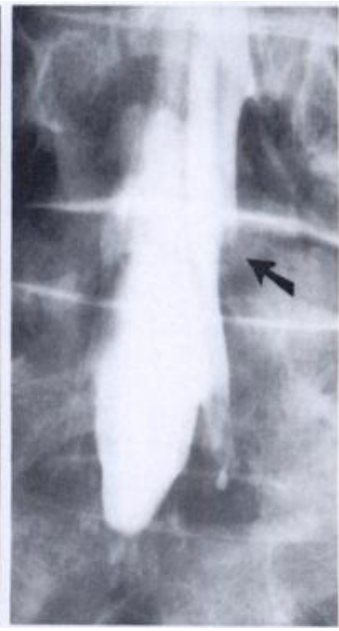

Fig. 5b
Discogram confirming an abnormal L4/L5 disc with a posterior leak of contrast medium, and radiculogram showing non-filling of the L5 root suggestive of a protrusion at $\mathrm{L} 4 / 5$.

unrewarding exploration, and also to exclude the rare possibility of a tumour.

It has been argued that water-soluble myelography is the benchmark investigation to exclude nerve root dysfunction (Rothman 1984). But its accuracy varies from 70 to $96 \%$ (Hudgins 1970; Nachemson 1976; Haughton et al. 1982; Bell et al. 1984; Morris et al. 1986) and it has a significant morbidity (Grainger et al. 1976; Baker et al. 1978). It involves considerable radiation, 


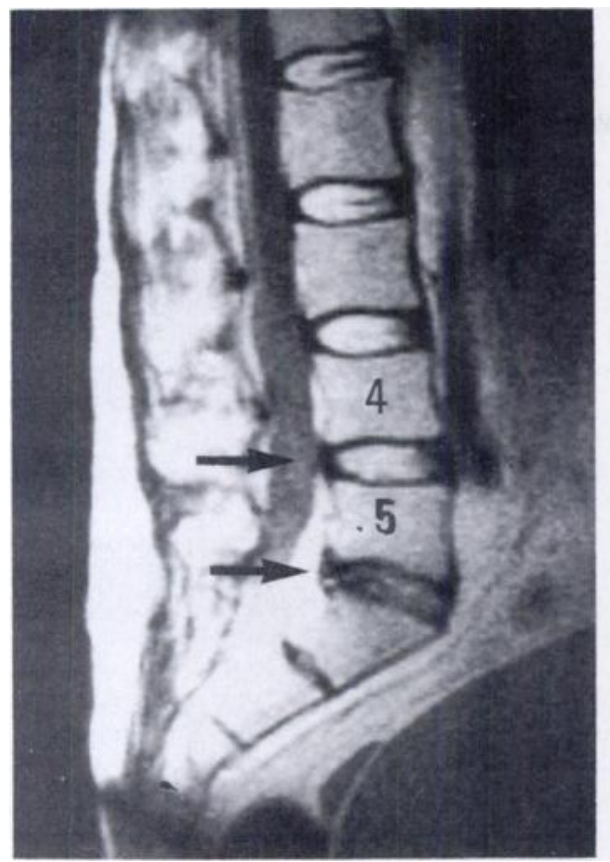

Fig. 6

$T_{2}$ weighted spin-echo sagittal image showing a marked reduction in signal from the nucleus at the $\mathrm{L} 5 / \mathrm{S}$ I disc but only a slight reduction at the L4/5 level.

technical skills and admission of the patient. Although it is a dynamic study, it directly shows only the subarachnoid space and its contents; the cause of any abnormality must be inferred. Because of the varying size of the epidural space, diagnostic accuracy is poor at the lumbosacral level where the thecal sac is narrow and the spinal canal larger (Raskin and Keating 1982; Keiffer et al. 1982).

MRI has the advantage of being an out-patient procedure which is less unpleasant for the patient and does not involve ionising radiation. The whole lumbar spine can be examined in the sagittal, axial and coronal planes and the introduction of surface coil imaging has improved considerably the quality of images.

Our study of a preselected group of patients showed that MRI was more accurate than radiculography in identifying disc protrusions, and gave no false negatives. All the discs proven to be abnormal demonstrated a decreased signal from the nucleus when $T_{2}$ weighted spin-echo or STIR sequences were used. In all, $70 \%$ of all protrusions were visualised on the sagittal scans alone; this was invaluable in identifying levels of abnormality, helping to direct transverse studies and reduce scanning time to an acceptable level. The first of two false positive results, was caused by a combination of disc bulge and bony stenosis; this indicates the difficulty in identifying the bony margins of the spinal canal on axial images produced with low field strength resistive magnets. In the second false positive a disc protrusion was clearly identified on the sagittal images and later demonstrated by discography (Figs $3 \mathrm{a}$ and $3 \mathrm{~b}$ ), but no herniation was found at operation. The fact that the patient's symptoms continued strongly suggests that the failure was surgical rather than one of diagnostic imaging.

The discrepancy between the imaging techniques was due largely to doubtful radiculographic studies, most of them at L5/S1 with its relatively large epidural space. We agree with Modic et al. (1986) that MRI is more accurate at this level, which accounted for $52 \%$ of the disc protrusions in our series. Although both methods of imaging were evaluated by independent viewers, this was done retrospectively, which may have put radiculography at a slight disadvantage; this investigation is normally a dynamic study and therefore subtle abnormalities may be missed on reviewing static records.

Another advantage of MRI is that it allows assessment of the morphology of the intervertebral discs. We found that $67 \%$ of our patients had multiple level disc degeneration, a much higher incidence than expected as part of the normal ageing process (Powell et al. 1986). Our previous study of adolescents with proven disc herniation gave similar results (Gibson et al. 1987), but it is uncertain whether these series are of groups of patients at special risk of developing further problems.

One of the main criticisms of MRI is the capital expenditure and maintenance costs. However, it is accurate, and more comfortable for the patient, who may not need admission for other imaging investigations. We are starting a socio-economic study in the hope of establishing the place and cost of this versatile technique.

We would like to extend our gratitude to $\mathrm{Mr} \mathrm{S}$. Chipperfield for performing the MRI scans, Mr J. K. Webb for allowing us to study his patients and Dr B. J. Preston for performing the radiculograms. Also our special thanks to Mrs P. Tuska and Mrs T. Simpson for preparing the manuscript and the Audio-Visual Department at the University Hospital, Nottingham, for providing the illustrations.

No benefits in any form have been received or will be received from a commercial party related directly or indirectly to the subject of this article.

\section{REFERENCES}

Baker RA, Hillman BJ, McLennan JE, Strand RD, Kaufman SM. Sequelae of metrizamide myelography in 200 examinations. $A J R$ 1978;130:499-502.

Bell GR, Rothman RH, Booth RE, et al. A study of computer-assisted tomography. II: Comparison of metrizamide myelography and computed tomography in the diagnosis of herniated lumbar disc and spinal stenosis. Spine 1984;9:552-6.

Bydder GM, Young IR. MR imaging: clinical use of the inversion recovery sequence. J Comput Assist Tomogr 1985;9:659-75.

Chafetz NI, Genant HK, Moon KL, Helms CA, Morris JM. Recognition of lumbar disc herniation with NMR. $A J R$ $1983 ; 141: 1153-6$.

Edelman RR, Shoukimas GM, Stark DD, et al. High-resolution surfacecoil imaging of lumbar disk disease. AJR 1985;144:1123-9.

Gibson MJ, Buckley J, Mawhinney R, Mulholland RC, Worthington BS. Magnetic resonance imaging and discography in the diagnosis of disc degeneration. J Bone Joint Surg [Br] 1986a;68-B:369-73.

Gibson MJ, Buckley J, Mulholland RC, Worthington BS. The changes in the invertebral disc after chemonucleolysis demonstrated by magnetic resonance imaging. J Bone Joint Surg $[\mathrm{Br}]$ $1986 \mathrm{~b} ; 68-\mathrm{B}: 719-23$. 
Gibson MJ, Szypryt Ep, Buckley JH, Worthington BS, Mulholland RC. Magnetic resonance imaging of adolescent disc herniation. $J$ Bone Joint Surg [Br] 1987;69-B:699-703.

Grainger RG, Kendall BE, Wylie IG. Lumbar mylography with metrizamide: a new non-ionic contract medium. $B r J$ Radiol $1976 ; 49: 996-1003$.

Han JS, Kaufman B, Yousef SJE, et al. NMR imaging of the spine. AJR $1983 ; 141: 1137-45$

Haughton VM, Eldevik OP, Magnaes B, Amundsen P. A prospective comparison of computed tomography and myelography in the diagnosis of herniated lumbar disks. Radiology 1982;142:103-10.

Hudgins WR. The predictive value of myelography in the diagnosis of ruptured lumbar discs. J Neurosurg 1970;32:152-62.

Keiffer SA, Sherry RG, Wellenstein DE, King RB. Bulging lumbar intervertebral disk: myelographic differentation from herniated disk with nerve root compression. AJR 1982;138:709-16.

Mixter WJ, Barr JS. Rupture of the intervertebral disc with involvement of the spinal canal. $N$ Engl J Med 1934;211:210-5.

Modic MT, Weinstein MA, Pavlicek W, et al. Nuclear magnetic resonance imaging of the spine. Radiology 1983;148:757-62.

Modic MT, Pavlicek W, Weinstein MA, Boumphrey F, Ngo F, Hardy R, Duchesnau PM. Magnetic resonance imaging of intervertebral disk disease : clinical and pulse sequence considerations. Radiology 1984;152:103-11.

Modic MT, Masaryk T, Boumphrey F, Goormastic M, Bell G. Lumbar herniated disk disease and canal stenosis: prospective evaluation by surface coil MR, CT and myelography. $A J R$ 1986;147:757-65.
Morris EW, Di Paola M, Vallance R, Waddell G. Diagnosis and decision making in lumbar disc prolapse and nerve entrapment. Spine 1986;11:436-9.

Nachemson AL. The lumbar spine: an orthopaedic challenge. Spine 1976;1:59-71.

Norman D, Mills CM, Brant-Zawadzki M, et al. Magnetic resonance imaging of the spinal cord and canal: potentials and limitations. AJR 1983;141:1147-52.

Powell MC, Wilson M, Szypryt EP, Symonds EM, Worthington BS. Prevalence of lumbar disc degeneration by magnetic resonance in symptomless women. Lancet 1986 ;ii:1366-7.

Raskin SP, Keating JW. Recognition of lumbar disk disease: comparison of myelography and computed tomography. $A J N R$ 1982;3:349-55.

Rothman RH. A study of computer-assisted tomography. Spine 1984;9:548.

Skalpe IO, Amundsen P. Lumbar radiculography with metrizamide: a non-ionic water-soluble contrast medium. Radiology 1975;115:91-5.

Schenck JF, Foster TH, Henkes JL, et al. High field surface-coil MR imaging of localized anatomy. AJNR 1985;6:181-6.

Williams AL, Haughton VM, Meyer GA, Ho KC. The computed tomographic appearance of the bulging annulus. Radiology $1982 ; 142: 403-8$.

Williams AL, Haughton VM, Syvertsen A. Computed tomography in the diagnosis of herniated nucleus pulposus. Radiology 1980;135:95-9. 